\title{
THE DEVELOPMENT OF THE INSTRUMENTATION AND CONTROL SYSTEM FOR A PALM KERNEL NUTS DRIER
}

\author{
'Babalola, M. T. and ${ }^{2}$ Ajagunna, A.O \\ 'Department of Physics, Federal University of Technology, Akure, Nigeria. \\ ${ }^{2}$ Department of Physics, Adekunle Ajasin University, Akungba Akoko, Nigeria.
}

\begin{abstract}
The electronic instrumentation system for a palm kernel drier was designed, constructed, tested and found to perform satisfactorily. Type $\mathrm{K}$ thermocouple was used to monitor the temperature of the drying chamber. A control circuit for presetting and regulating the temperature of the drier was also developed. This permits the temperature of the drying chamber to be fixed between ambient temperature and $100^{\circ} \mathrm{C}$.
\end{abstract}

Keywords: Thermocouple, elecronic instrumenetation, control circuits, drier

\subsection{INTRODUCTION}

There has never been enough food available to feed the whole human family properly. According to Robbele, et. al [1], even in Great Britain, where nowadays, food is very plentiful, there was recorded famine one year in every ten. Mechanical farming, the liberal use of fertilizers, irrigation and pest control, together with the application of food technology in preserving food between harvests have, in recent years, removed food shortages in the industrialized countries. The shortages remain however in the non-industrialized countries, such as Nigeria. The present-day food industry has its origin in pre-history when the first food processing took place to preserve foods against spoilage, or to improve their nutritional quality. Food processing equipment now allows increasingly sophisticated control of processing conditions to achieve the twin aim of reduced processing costs and reduced damages (particularly heat damage) to the sensory and nutritional qualities of foods. Energy saving is also an important feature of most food processing equipment [2].

According to Robbele et.al [1], collectively, oil crops and their products is the second most valuable commodity in world trade. Production and trade in these commodities have expanded rapidly in response to a growing world population and rising standard of living.

Nig. J. Pure Appl. Pliys. (2005) Vol. 4 pp 46-53. Printed in Nigeria, ISSN 1596-0862. E-mail: njpapfuta(a)yahoo.com. For rights of reproduction and web access, contact African Journals Online, UK, www. inasp.ajol/journals/njpap
Some oil crops such as groundnuts are used directly as food. Some others, for example, palm kernel nuts are processed by pressing and extracting to obtain fat or oil and cake. Oils and fats are vital components of the human diet because they are important sources of energy and act as carriers of fat-soluble vitamins. The chief significance of the oil seeds and their products is to satisfy the vital demand for oils and fats and high protein animal feed. About $80 \%$ of the fats and oils produced are used for edible purposes and the rest is processed in the technical sector [3]. Some of the edible uses of vegetable oil are for cooking, fats for the bakery, confectionary industry and mayonnaise manufacture, margarine, oils for the fish and canning industry, salad oils and shortenings. Technically, oil is used for the production of chemicals, candles, cosmetics, linoleum, lubrication, paints and resins, coating, pharmaceutical product, plastic coatings and soaps to mention a few. This everincreasing demand for oil has necessitated our work in this area.

Nigerians have developed and acquired taste for imported vegetable oil, which in recent times, comes primarily from Malaysia and other countries around her. Palm trees grow abundantly in the southern part of Nigeria. From its fruits, one can obtain palm oil and palm kernel oil (PKO). PKO is a good replacement for imported edible vegetable oil. Therefore, in order to conserve our foreign exchange earnings, it is imperative that efforts should be geared towards improving the Nigerian crude palm kernel oil.

Products of palm kernel nuts such as palm kernel oil (PKO) and soap are in great demand by many consumers. Thousands of people in the southern part of Nigeria are engaged in the business because of its economic importance locally. For example. the locally 
processed black PKO is used medically as an antidote against poison, in cosmetics as body and hair cream and for producing the local black soap. The list is not exhaustive. However, the major setback it has as a cooking ingredient is due to its bad taste, awful odour and black colour, which emanates from the contamination of the oil by soot during the drying process. The application of too much heat burns the nuts and turns them black. However, it is realized by the elite class that PKO can be used as edible oil if the nuts are properly dried and the oil is extracted by pressing. Insufficiently dried kernel

nus have show a much higher rate of increase in free fatty acid (FFA), which lowers the quality of the product [4].

During the dry season, sun drying is found to be efficient and clean. But sun drying is extremely difficult especially during rainy season. This problem was initially brought to our attention by a local user of the product who had carried out the drying process using the local methods listed in table 1 , all of which failed to yield the desired result because of some attendant problems.

Table 1: Some sources of heating of palm kernel nuts locally and attendant problems

\begin{tabular}{|c|c|}
\hline Source of heating & Attendant problem \\
\hline Fire wood & Nuts acquired a lot of smoke and soot \\
\hline Diesel engine & Nuts acquired a lot of smoke and soot \\
\hline Electricity & $\begin{array}{l}\text { Inefficient harnessing of the heat because the heat from the source did not } \\
\text { get to the nuts }\end{array}$ \\
\hline
\end{tabular}

The aim of this work is to design and construct the electronic instrumentation and control systems for presetting and regulating the temperature of palm kernel nuts drier.

\subsection{RESEARCH METHODOLOGY \\ The palm kernel nuts drier was} developed. It has two major parts namely: the control system and the housing unit, that is, the body of the drier. The design of the instrumentation and control systems are discussed in this paper while the construction of the housing unit, and the characteristics and performance tests of the drier have already been reported in another paper [5].

\subsection{Designs and Construction of Control Circuits and System}

The knowledge of the physical and thermal properties of any product is a prerequisite for the design of equipment for processing of the product [6]. According to Jorgensen [7], palm kernel nuts are best dried with hot air flowing over them at a temperature of $80^{\circ} \mathrm{C}$. The drier was therefore designed to accommodate a preset temperature variable between $27^{\circ} \mathrm{C}$ (ambient temperature) and $100^{\circ} \mathrm{C}$. The design of the temperature monitoring system and other circuits used in this work is described below.

\subsection{The Thermocouple Characteristics}

The thermocouple was used as a temperature sensor for monitoring the temperature of the drying chamber. Two identical copper-constantan thermocouples were locally constructed and connected as shown in figure 1. The LM 324 operational amplifier was used as a differential amplifier of voltage gain 100. The amplifier amplifies the thermo-emf produced by the thermocouples as the temperature of the hot junction varies from $27^{\circ} \mathrm{C}$ to $100^{\circ} \mathrm{C}$. The readings obtained showed that the output voltage varied linearly with temperature. The maximum output voltage was $412 \mathrm{mV}$ at $100^{\circ} \mathrm{C}$, giving a thermocouple constant of $41.2 \mu \vee \rho^{\circ} \mathrm{C}$. According to R S Catalogue [8], the thermocouple constant for a class $\mathrm{K}$ type is $40.6 \mu \mathrm{V} /{ }^{\circ} \mathrm{C}$. Thus the error in using the locally made thermocouple is less than $1.5 \%$.

It is not feasible to maintain the ice point in a farm settlement where the equipment is desired. A cold junction compensator was designed to eliminate the ice point. The experimental set-up is shown in figure 2. The resistors $R_{2}, R_{4}, R_{5}$, and $R V_{1}$ were chosen so that under steady conditions, the zener diode $Z_{1}$ draws a current of $12 \mathrm{~mA}$ thus ensuring that the voltage across it is constant. $R V_{1}$ was adjusted until the output voltage at $100^{\circ} \mathrm{C}$ as read on a digital multimeter was $412 \mathrm{mV}$. The water was allowed to cool down towards the room temperature. The readings obtained agreed with the readings obtained in figure 1 . This shows that the cold junction compensator was adequate.

\subsection{The Thermocouple Amplifier}

In order to read the temperature of the drying chamber, the output signal from the thermocouple was fed to an analogue-to-digital converter (ADC), whose output in turn drove a 
digital display. At $100^{\circ} \mathrm{C}$, the $\mathrm{ADC}$ required a signal voltage of $1000 \mathrm{mV}$ whereas the thermocouple output was $4.12 \mathrm{mV}$. Consequently an amplifier was inserted between the thermocouple and the ADC. The amplifier gain is about 250 . To obtain this large gain, a two-stage amplifier was adopted. The circuit diagram is shown in section II of figure 3. Stage $A$ is a differential amplifier whose voltage gain $A_{v}$ is given by $A_{v}=R_{2} / R_{1}=22$. Stage $B$ is a non- inverting amplifier whose voltage gain equals $\left(R_{6}+R_{7}\right) / R_{6}$. The potentiometer $R V_{3}$ was included in the feedback network to trim the gain of the composite amplifier to 250 . When the circuit was constructed, the potentiometer $\mathrm{RV}_{3}$ was adjusted to set the reading of the display to exactly 100.0 when the temperature of the heating chamber was $100^{\circ} \mathrm{C}$. After this setting of the thermocouple amplifier, the thermocouple was installed in the heating chamber of the drier.

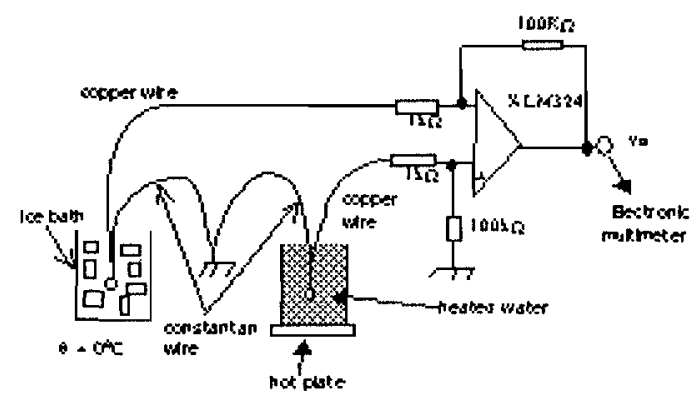

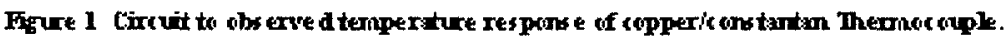

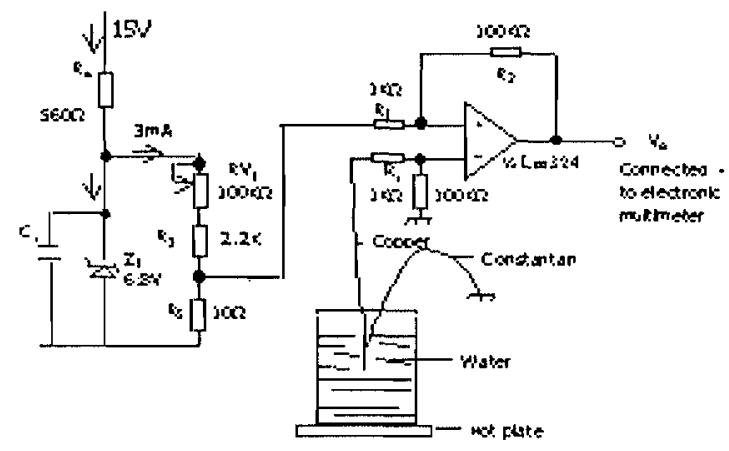

Figure 1 Circuit to obbin coli junction correctar.

\subsection{The Analogue To Digital Converter}

Figure 3 shows a circuit diagram consisting of the thermocouple amplifier, the $\mathrm{ADC}$ and the display. The device chosen for the ADC is the TC7 107A IC manufactured by Harris semiconductor. From the specifications of the manufacturer [9], the device has the following advantages: it is inexpensive and readily available, it digitizes both positive and negative voltages, it requires very few external components and it can directly drive commonanode L.E.D seven-segment displays. The displays are driven directly rather than being multiplexed. Therefore, the output is free of glitches which normally accompany multiplexed displays. The segment currents are internally limited to $8 \mathrm{~mA}$. Hence, no external current limiting resistors are required for the segments. The input resistance is very high (about $10^{12} \Omega$ ) thus ensuring that the IC is not loaded by the internal resistance of the signal source. The IC has a low temperature drift and finally, the autozero cycle eliminates the need for zero adjustment.

The TC7107A IC works on the dual slope integration technique. The frequency of the internal clock depends on the $R_{\text {osc }}$ and $C_{\text {osc }}$ connected to pins 38,39 , and 40 of the device. The values of the components used in this work gave a frequency of $48 \mathrm{kHz}$. Each conversion from analogue to digital signal requires 16000 clock pulses. Therefore each conversion is completed in about 0.33 second. The display 


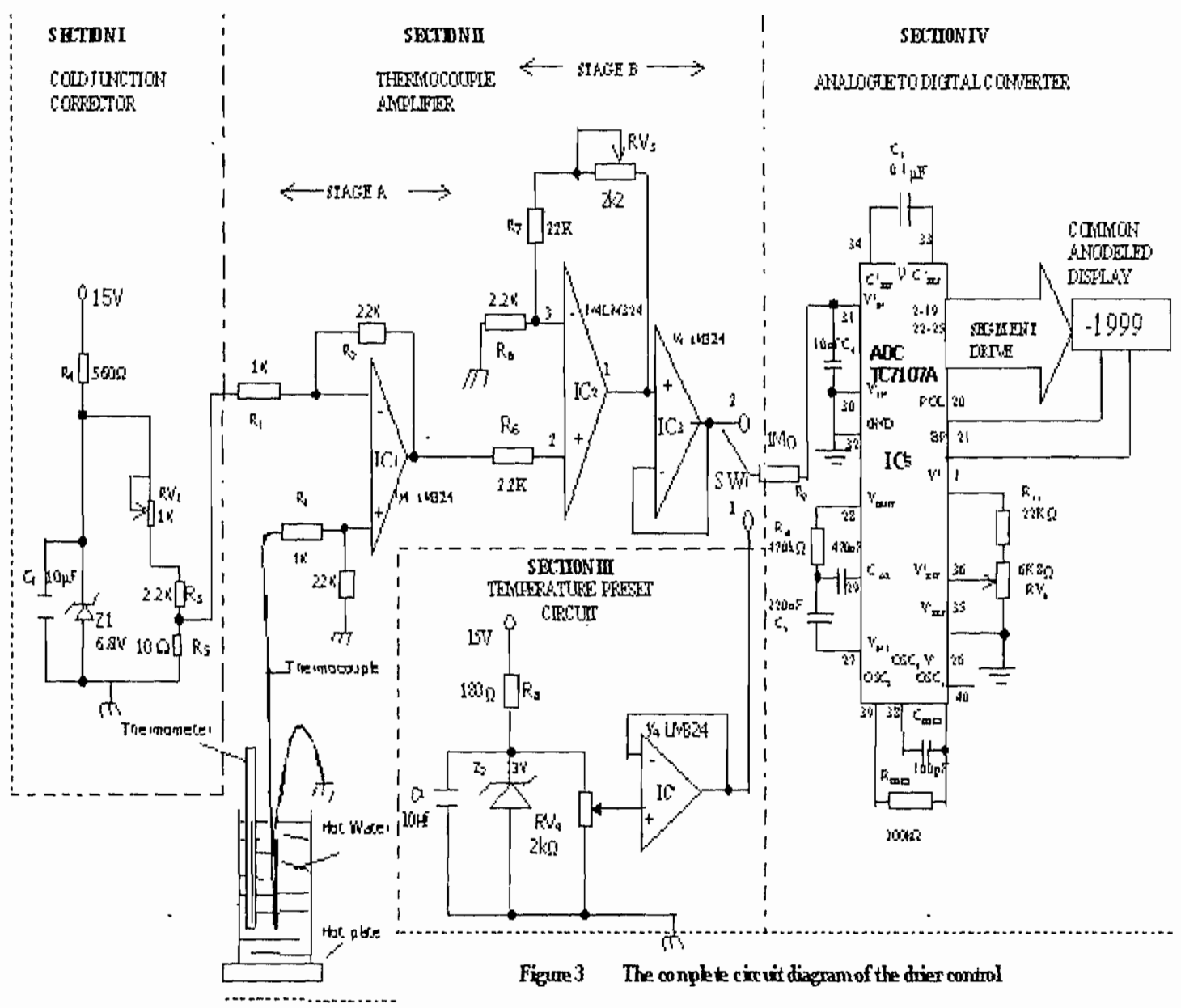

reads -1999 when the input voltage is $-2.00 \mathrm{~V}$ and 1999 when the input voltage is $2.00 \mathrm{~V}$. The counter sensitivity is $1 \mathrm{mV}$ per count. The naximum temperature of the drier was fixed at $100^{\circ} \mathrm{C}$ for which the display would read 1000 . This reading is converted to 100.0 by turning on the decimal point after the second zero. At this temperature, the input signal required by the $\mathrm{ADC}$ is $1000 \mathrm{mV}$.

\subsection{Description of The Temperature Preset Circuit}

The drier was designed to operate at different temperatures between $27^{\circ} \mathrm{C}$ (ambient temperature) and $100^{\circ} \mathrm{C}$. The diagram of the temperature preset circuit is shown in section III of figure $3 . Z_{2}$ is a $13 \mathrm{~V}$ zener dicde while $R V_{4}$ is a 10-turn pot, thus ensuring that the voltage at the non-inverting input of $\mathrm{IC}_{+}$varies between $0 \mathrm{~V}$ and $13 \mathrm{~V}$ in very short steps. The switch $\mathrm{SW}_{1}$ was put in position $1, \mathrm{RV}_{+}$was adjusted unti the display read the desired temperature of the drier. Subsequently, SW, was switched to position 2 to monitor the actual temperature of the drying chamber. $\mathrm{IC}_{4}$ functions as a voltage follower to provide a high load resistance to the zener circuit and a low source resistance to the succeeding circuit. 


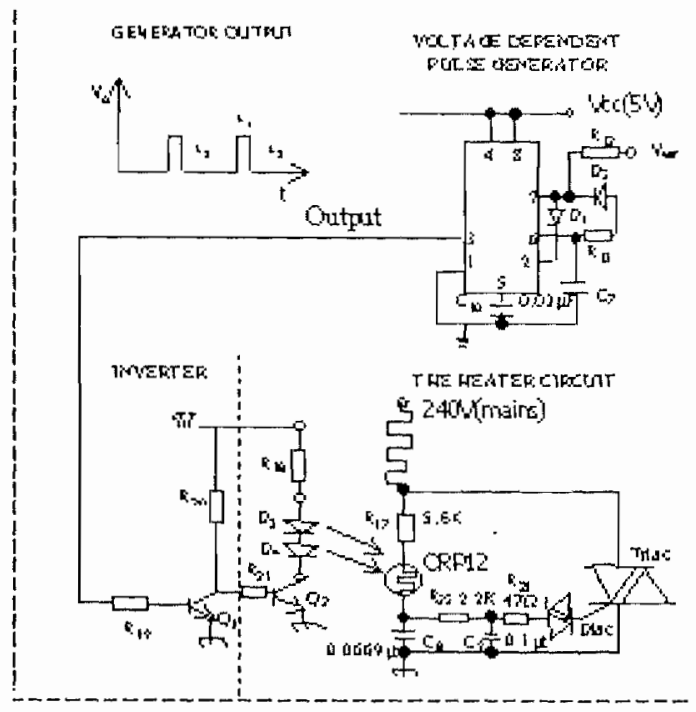

Figure 4 The Heater Controller.

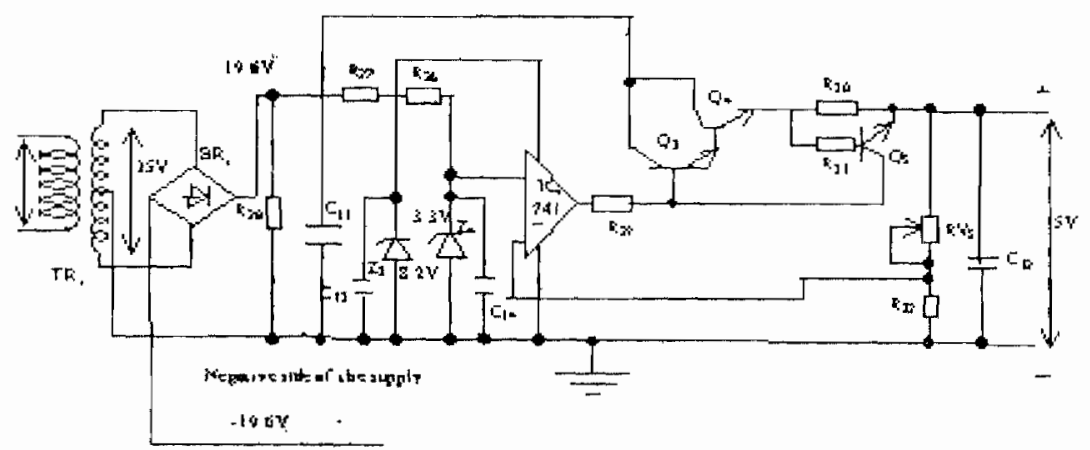

Figure 5 The circuit disgram of the 5 V s ypply.

\subsection{Description of The Heater Controller}

The circuit diagram of ihe heater controller is shown in figure 4 . It consists of a pulse generator, an inverter, and a thyristor circuit. The pulse generator was built around $I_{6}$, a 555 timer. Detailed description of the 555 timer and its applications can be found in Hall [10]. $\mathrm{IC}_{6}$ was used as an astable multivibrator. The supply voltage to the timer is $5 \mathrm{~V}$. In the interval $t_{1}$, the capacitor $C_{7}$ charges through $R_{12}$ and the diode $D_{1}$ from a target voltage of $V_{a r}$. $V_{a r}$ is the output voltage of a comparator (not shown on the diagram) which compares the actual temperature of the heating chamber and the preset temperature. In the interval $t_{2}$, the capacitor discharges through $R_{13}$ and $D_{2}$, to a target voltage of $0 \mathrm{~V}$. The output signal taken at pin 3 of $\mathrm{IC}_{6}$ is a rectangular wave. For a large value of $\mathrm{V}_{\mathrm{ar}}$, saly $15 \mathrm{~V}$ (which occurs when the preset temperature is higher than the actual temperature of the drying chamber) the charging time $t_{1}$ is smaller than the discharging time $t_{2}$.

\section{Working of the heater circuit}

The triac is an excellent device for a full wave ac power control. This circuit uses a phase triggering technique in which $\mathrm{R}^{*}$ and $\mathrm{C}_{8}$ provide a potential divider and a phase shift network. The voltage across $\mathrm{C}_{8} \mathrm{~V}_{c 8}$ is given by

$$
\mathrm{V}_{\mathrm{C} 8}=\mathrm{V}_{\mathrm{in}} /\left(1+\mathrm{j} \omega \mathrm{R} * \mathrm{C}_{8}\right) \text {. }
$$

Where $V_{\text {in }}$ is the applied ac voltage, $R *$ is $R_{17}$ plus the resistance of ORPI2. In this work, $\omega \mathrm{R}^{*} \mathrm{C}_{8}<<1$ in the interval $t_{2}$, hence $\mathrm{V}_{c 8}$ is nearly equal to $V_{\text {in }}$

$$
\mathrm{V}_{\mathrm{c} 8}=\mathrm{V}_{\mathrm{in}}=220 \sqrt{2} \mathrm{Sin} \omega \mathrm{t}
$$

$V_{C 8}$ is fed to a 'slave' network $\mathrm{R}_{22} \mathrm{C}_{9}$. When the voltage across $\mathrm{C}_{9}$ exceeds the break-over voltage of the diac, the diac starts to conduct, thereby firing the triac into conduction and power is applied to the heater.

The diac used in this work is $\mathrm{Br} 100$. Its break-over voltage $V_{B 0}=32 \mathrm{~V}$. The diac therefore passes a trigger pulse to the triac gate $5^{\circ}$ after the start of each half cycle of the applied voltage, implying that almost the full power is applied to the heater. The purpose of the 'slave' 
network is to prevent a large change in $V_{c 8}$ when the diac discharges $C_{9}$.

But in the interval $t_{1}$, the resistance of ORP12 is very large, $\omega \mathrm{R}^{*} \mathrm{C}_{8} \gg 1$. The voltage $V_{C 8}$ is not enough to turn the diac on. The heater is therefore off.

Referring to figure 4, suppose the power is just applied to the circuit, the differential voltage $V_{t i t}$ is maximum and higher than $V_{c c}$. The pulse generator has a rectangular waveform inserted in figure 4 . In the short time interval $t_{1}$, the output voltage is driven high. The transistor $Q_{i}$ turns heavily on to saturation and the transistor $\mathrm{Q}_{2}$ is off. There is no current through the light emitting diodes $\mathrm{D}_{3}$ and $\mathrm{D}_{4}$. The heater is therefore off.

In the long time interval $t_{2}$, the output signal is low, the transistor $Q_{1}$ turns off and $Q_{2}$ is driven to saturation. The light emitting diodes $\mathrm{D}_{3}$ and $\mathrm{D}_{4}$ turn on and they illuminate the light dependent resistor ORP12 whose resistance falls from $1 M \Omega$ to about $4 k \Omega$. At this interval both the diac and triac are fired. A large current flows through the heater for several cycles of the mains ac supply. As the temperature of the drying chamber rises, the differential voltage (Var) falls. And so, the charging period $t_{1}$ increases, while the discharging time $t_{2}$ decreases. The duty cycle of the rectangular waveform increases. The interval during which the heater is on decreases. The control circuit is able to adjust its pulse width in accordance with temperature difference between the pre-set and the actual temperature and so drives the power circuit accordingly.

\subsection{Description of The Power Supplies}

The various stages of this equipment require the following de voltages: (a) $\pm 5 \mathrm{~V}$ for the operational amplifiers and (b) $15 \mathrm{~V}$ for the comparators. Each supply was obtained from the mains ac source.

For the $+5 \mathrm{~V}$ power supply of output current $0.5 \mathrm{~A}$ (maximum), a $240 \mathrm{~V}, 50 \mathrm{~Hz}$ ac source is applied to the primary winding of a centre-tapped transformer TR 1 ( see figure 5). The voltage at the secondary winding of the transformer is $15 \mathrm{~V}_{\mathrm{rms}}$. The bridge rectifier $B R_{1}$ converts the ac voltage to $19.6 \mathrm{~V} \mathrm{dc} . C_{11}$ is the filter capacitor while $R_{28}$ serves as the bleeder resistor to the filter capacitor. The zener diode $Z_{7}$ puts the $V_{c c}$ for the op amp $\mathrm{IC}_{7}$ at $8.2 \mathrm{~V}$ while the zener diode $Z_{6}$ fixes the voltage at the non-inverting input of the op-amp at $3.3 \mathrm{~V}$. I IC 7 compares this voltage with a fraction of the output voltage $V_{0}$.

$$
V_{0}=(1+y / x) V_{z 4}
$$

where $V_{Z 4}$ is zener voltage of diode $Z_{4}$. $R V_{5}$ was adjusted to put the output voltage at exactly
$5.0 \mathrm{~V}$. The transistor $Q_{5}$ is the current limiter. When the load current exceeds $0.5 \mathrm{~A}$, transistor $Q_{5}$ turns on thereby robbing $Q_{3}$ of its base current. The output voltage drops low instantly to protect the series transistor $Q_{4} . Q_{4}$ was mounted on a suitable heat sink because it dissipates considerable energy. The $-5 \mathrm{~V}$ supply was obtained in a similar way with pnp transistors replacing npn transistors and the power supply line to the collector of the series transistor is taken from $-19.6 \mathrm{~V}$. For the $15 \mathrm{~V}$ supply, the circuit is the same as that shown in figure 5 except that the ratio $y: x$ in equation 3 was changed to make $V_{o}$ equal to $15 \mathrm{~V}$

\subsection{Overall Circuit Construction}

Printed circuits were produced using photo-resist boards. These are copper-clad epoxy glass boards. The boards have positive photo-resist surfaces protected by a peel-off plastic film. Using the circuit diagrams, components were inserted into their respective locations. Masking tape was used to keep components in place and then the board overturned for soldering. Soldering was carried out and excess component leads trimmed. The wired board was tested to ensure that it was working properly.

\subsection{Description of The Mechanical Part of} The Drier

A heavily lagged rectangular-shaped drier was constructed and compartmentalised into the drying chamber, the heater chamber and the electronic control section. The heater chamber houses two 1500W electric heaters. A blower blows the hot air around the heaters into the drying chamber. All the electronic circuits used in the drier (shown in figures 3,4 and 5) are racked together in the electronic control section. This compartment is thermally insulated from the heater section to avoid overheating the electronic components there. The temperature sensor is a thermocouple. It was passed through a duct in the double wall of the drier through a small hollow pipe which has been welded to the roof of the drying chamber. The thermocouple hot junction projects out of the hollow pipe into the drying chamber.

\subsection{PERFORMANCE TEST OF THE CONTROL CIRCUIT.}

The preset temperature was set at $40^{\circ} \mathrm{C}$. The door of the drier was closed. The temperature of the heating chamber was monitored at intervals of 30 seconds. The measurements were repeated for preset 
temperatures of $50^{\circ} \mathrm{C}, 60^{\circ} \mathrm{C}, 70^{\circ} \mathrm{C}, 80^{\circ} \mathrm{C}, 90^{\circ} \mathrm{C}$ and $100^{\circ} \mathrm{C}$. The readings obtained are shown in Table 1. Figure 6 shows the graph of temperature versus time. The graphs show that the temperature of the heating chamber rose steeply at switch-on and gradually moved towards the preset temperature. The preset temperature was ultimately attained without excessive ivershooting. The experiment confirms that the control circuit is effective.

Table 1: Test results showing the Temperature - Time response of the drier

\begin{tabular}{|r|r|l|l|l|l|l|l|l|}
\hline \multirow{2}{*}{$\begin{array}{l}\text { SERIAL } \\
\text { NUMBER }\end{array}$} & \multirow{2}{*}{ TIME(S) } & \multicolumn{7}{|c|}{ TEMPERATURES } \\
\cline { 2 - 9 } & & $40^{\circ} \mathrm{C}$ & $50^{\circ} \mathrm{C}$ & $60^{\circ} \mathrm{C}$ & $70^{\circ} \mathrm{C}$ & $80^{\circ} \mathrm{C}$ & $90^{\circ} \mathrm{C}$ & $100^{\circ} \mathrm{C}$ \\
\hline 1 & 0 & 32 & 33 & 33 & 32 & 34 & $34 / 35$ & 34 \\
\hline 2 & 30 & 35 & $36 / 37$ & 37 & 37 & 39 & 40 & 40 \\
\hline 3 & 60 & $40 / 41$ & 42 & 41 & 42 & 44 & 45 & 45 \\
\hline 4 & 90 & - & 47 & 45 & 47 & 49 & 51 & 53 \\
\hline 5 & 120 & - & $50 / 51$ & 50 & 51 & 55 & 57 & 59 \\
\hline 6 & 150 & - & - & 54 & 56 & 59 & $62 / 63$ & 65 \\
\hline 7 & 180 & - & - & $59 / 60$ & 60 & 64 & 68 & 71 \\
\hline 8 & 210 & - & - & - & 66 & 70 & 74 & 76 \\
\hline 9 & 240 & - & - & - & $70 / 71$ & 74 & 79 & 82 \\
\hline 10 & 270 & - & - & - & - & 77 & 82 & 87 \\
\hline 11 & 300 & - & - & - & - & 80 & 86 & 92 \\
\hline 12 & 330 & - & - & - & - & $80 / 81$ & 89 & 96 \\
\hline 13 & 360 & - & - & - & - & - & $90 / 91$ & $98 / 99$ \\
\hline 14 & 390 & - & - & - & - & - & - & $99 / 100$ \\
\hline 15 & 420 & - & - & - & - & - & - & $99 / 100$ \\
\hline
\end{tabular}

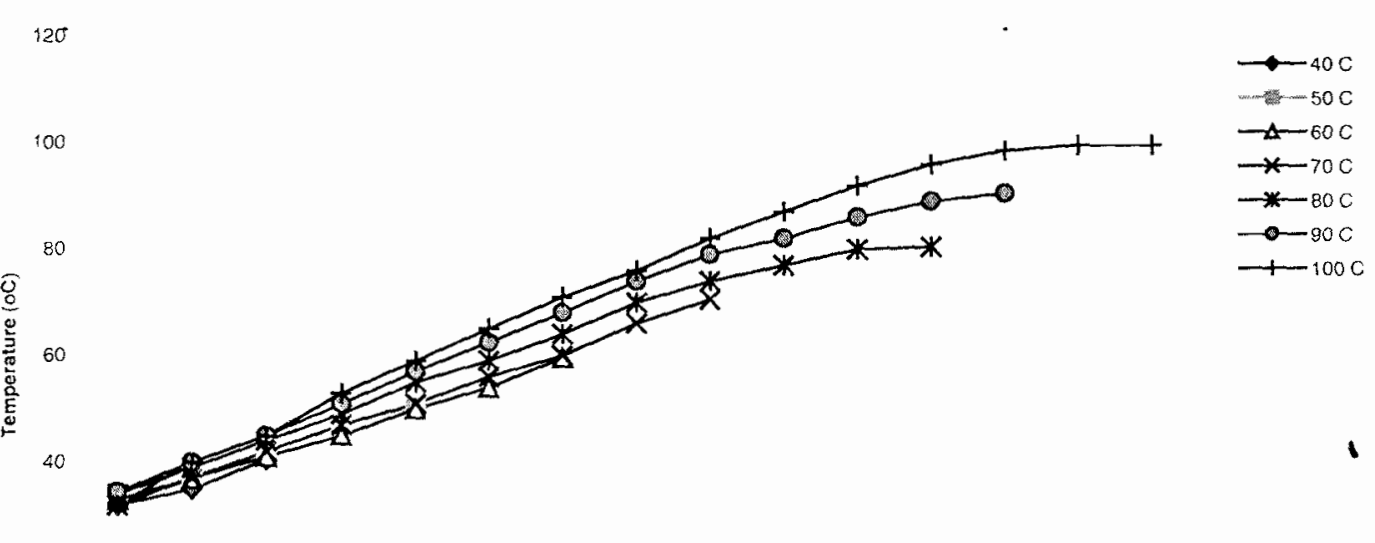

20

O

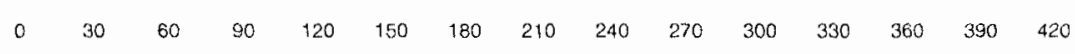

Time Response (Seconds)

Figure 6 Chart showing the drier temperature control properties at different preset Temperatures

To test the performance of the drier, a sample of the palm kernel nuts of mass $4 \mathrm{~kg}$ was loaded into the drier. The temperature of the heating chamber was kept constant at $40^{\circ} \mathrm{C}$ and the heater was turned on for 60 minutes. The final mass of the nuts was measured. The moisture content of the nuts. $X$. was calculated using the relation: 
$X=$ original mass of nuts-mass of dry sample $\quad . \quad$. 4 . mass of dry sample

The measurements above were repeated for preset temperatures of $60^{\circ} \mathrm{C}, 80^{\circ} \mathrm{C}$, and $100^{\circ} \mathrm{C}$. The experiment (details of which are reported in [5]), showed that the moisture content reduced to $74 \%, 35 \%, 18 \%$, and $5 \%$ respectively for preset temperatures of $40^{\circ} \mathrm{C}$, $60^{\circ} \mathrm{C}, 80^{\circ} \mathrm{C}$, and $100^{\circ} \mathrm{C}$. It was therefore found that the drier is suitable for drying palm kernel nuts if operated at $80^{\circ} \mathrm{C}$ and above.

\section{REFERENCES}

1 Robbele, G.; Downey, R.K.; Ashri, A. (1989). Oil crops of the world. McGraw Hill Inc. U.S.A.

2. Fellows, P.J. (1990). Food Processing Technology: Principles and Practice. Second Edition. Ellis Horwood Limited, England.

3 Richter, H.J. and Knaut, J. (1984). Challenges to a mature industry; Marketing and economics of olechemicals in Western Europe. Journal of American Oil and Chemists' Society, $61(12), 160-175$.

4. Timms, R.E. (1985). Physical properties of Oils and mixtures of oil. Journal of the American Oil and Chemists' Society 62(2), $241 \div 249$.

5. Babalola, M.T. and Ajagunna A.O. (2004) Design and performance characteristics of a palm kernel nuts drier. Nigerian Journal of Pure and Applied Physics, 3, 8-14.

6. Mujunda, A.S. (1986) Drying of solids, Recent International Developments, Wiley Eastern New Delhi.

7. Jorgensen, H.K. (1985). Treatment of Empty Fruit Bunches for Recovery of Residual Oil and Additional Steam Production. Journal of American Oil \& Chemists Society. 62(2), 279.

8. RS Catalogue, (March - August 1993). International Edition pp, 502.

9 Microchip Technology Inc. Catalogue (2002).

10. Hall, D.V. (1989). Digital Circuit \& Systems, McGraw Hill (Int. Edition), Singapore. 